\title{
A comprehensive research agenda for zero leprosy
}

\author{
Peter Steinmann ${ }^{1,2^{*}}\left(\mathbb{D}\right.$, Courtenay Dusenbury ${ }^{3}$, David Addiss ${ }^{4}$, Fareed Mirza ${ }^{5}$ and W. Cairns S. Smith ${ }^{6}$
}

\begin{abstract}
Background: Leprosy control achieved dramatic success in the 1980s-1990s with the implementation of short course multidrug therapy, which reduced the global prevalence of leprosy to less than 1 in 10000 population. However, a period of relative stagnation in leprosy control followed this achievement, and only limited further declines in the global number of new cases reported have been achieved over the past decade.

Main text: In 2016, major stakeholders called for the development of an innovative and comprehensive leprosy strategy aimed at reducing the incidence of leprosy, lowering the burden of disability and discrimination, and interrupting transmission. This led to the establishment of the Global Partnership for Zero Leprosy (GPZL) in 2018, with partners aligned around a shared Action Framework committed to achieving the WHO targets by 2030 through national leprosy program capacity-building, resource mobilisation and an enabling research agenda. GPZL convened over 140 experts from more than 20 countries to develop a research agenda to achieve zero leprosy. The result is a detailed research agenda focusing on diagnostics, mapping, digital technology and innovation, disability, epidemiological modelling and investment case, implementation research, stigma, post exposure prophylaxis and transmission, and vaccines. This research agenda is aligned with the research priorities identified by other stakeholders.

Conclusions: Developing and achieving consensus on the research agenda for zero leprosy is a significant step forward for the leprosy community. In a next step, research programmes must be developed, with individual components of the research agenda requiring distinct expertise, varying in resource needs, and operating over different timescales. Moving toward zero leprosy now requires partner alignment and new investments at all stages of the research process, from discovery to implementation.
\end{abstract}

Keywords: Leprosy, Mycobacterium leprae, Priorities, Research, Strategy, Zero leprosy

\section{Background}

Following dramatic progress between 1980 and 2000, the control of leprosy (also known as Hansen's disease), and reduction of the deep-rooted stigma and discrimination against people affected by the disease, have slowed considerably over recent years [1, 2]. In 2019, 202185 new leprosy diagnoses were reported to the World Health Organization (WHO) [3]. The global implementation of multidrug therapy (MDT) for leprosy was

\footnotetext{
*Correspondence: Peter.steinmann@swisstph.ch

1 Swiss Tropical and Public Health Institute, Socinstrasse 57, 4051 Basel, Switzerland
}

Full list of author information is available at the end of the article a game-changer in the 1980s and 1990s [4]. The 1991 World Health Assembly (WHA) approval of a resolution to eliminate leprosy as a public health problem triggered the donation of MDT drugs to the WHO and innovations in leprosy case management and documentation, which led to a sharp reduction in the registered global prevalence of leprosy to less than 1 in 10000 population [5]. Unfortunately, this strategy did not have a sustained impact on disease incidence; success and the perception that leprosy was no longer a problem led to a loss of political commitment to leprosy control, resulting in reduced resource allocation [4]. original author(s) and the source, provide a link to the Creative Commons licence, and indicate if changes were made. The images or other third party material in this article are included in the article's Creative Commons licence, unless indicated otherwise in a credit line to the material. If material is not included in the article's Creative Commons licence and your intended use is not permitted by statutory regulation or exceeds the permitted use, you will need to obtain permission directly from the copyright holder. To view a copy of this licence, visit http://creativecommons.org/licenses/by/4.0/. The Creative Commons Public Domain Dedication waiver (http://creativeco mmons.org/publicdomain/zero/1.0/) applies to the data made available in this article, unless otherwise stated in a credit line to the data. 
In September 2016, during the 19th International Leprosy Congress in Beijing, leading stakeholders called for the creation of a partnership to advance zero leprosy to achieve true elimination. Following extensive consultations, the Global Partnership for Zero Leprosy (GPZL) (https://zeroleprosy.org/) was formally established in 2018. It has over 700 members with a broad range of experience and expertise, and is managed by a leadership team and secretariat. GPZL's vision of "no disease, no disability, and no discrimination/stigma" is in line with the targets and objectives of the WHO Global Leprosy Programme (https://www.searo.who.int/entity/global_ leprosy_programme/en/), the International Federation of Anti-Leprosy Associations (ILEP; https://www.ilepfedera tion.org/), the Sasakawa Health Foundation, Novartis International and other key stakeholders. Members of the partnership have aligned around a shared Action Framework to achieve WHO's 2030 global leprosy targets [6] through collaboration on country-led planning and capacity building, resource mobilization, and an enabling GPZL research agenda.

This Policy Platform describes the development, content and conclusions of the GPZL research agenda as well as the next steps in resourcing and implementing it. The leprosy community has diverse expertise and strong national and international dimensions, including in research, where the International Leprosy Association facilitates an International Leprosy Congress every three years. There are also national and regional leprosy associations, with a geographically-defined focus and often strong anchoring in local academic bodies. Global and local associations of people affected by leprosy, and non-governmental organisations working in leprosy, play an important role. Leprosy research is funded through grants from public and private bodies while national leprosy program directors and ministries of health are at the front line of defining implementation research needs. Consensus on any leprosy research agenda therefore has to involve all these stakeholders in order to be successful.

\section{Research agenda development}

The GPZL Leadership Team appointed a chair in early 2018 to coordinate the development of the research agenda, with support from a senior expert advisor and the GPZL Secretariat. A working group was established with subgroup facilitators who led discussions across eight topic areas that had been selected by the Leadership Team members as priorities: (i) diagnostics; (ii) mapping, digital technology and innovation; (iii) disability; (iv) epidemiological modelling and investment case; (v) implementation research; (vi) stigma; (vii) post-exposure prophylaxis (PEP) and transmission; and (viii) vaccines. An open call for participants was issued to recruit experts and persons who had experienced leprosy. The research agenda process strived to engage the diversity of the leprosy community as well as the broader neglected tropical diseases (NTD) community to ensure agreement and ownership of the research priorities. Overall, more than 144 persons from over 20 countries signed up to participate.

A mapping of past initiatives to define leprosy research priorities, including those conducted by the Leprosy Research Initiative (LRI; https://www.leprosyresearch .org/) and the Research to Stop Neglected Tropical Diseases Transmission Initiative (R2STOP; https://r2sto p.org/) provided a starting point. It was considered important that the research agenda be built on previous work and followed established principles for qualitative research (COREQ) [7]. The team also engaged with the NTD community through a panel discussion at the 2018 Coalition for Operational Research on NTDs (CORNTD; https://www.ntdsupport.org/cor-ntd) meeting in New Orleans, USA. The detailed research priorities for each of the 8 priority themes was published in Leprosy Review [8] along with a commentary [9]. The current article focuses on the context of the research priority identification and their significance.

\section{Research areas and priorities}

Similar to many other NTDs, leprosy is a complex condition in terms of its clinical and epidemiological characteristics, long-term medical and biological consequences (or effects), and intersections with socio-economic and cultural factors $[10,11]$. Several cross-cutting themes emerged during the working group and subgroup deliberations, including the need for integration between research efforts. To achieve breakthroughs, research projects may need to integrate multiple disciplines and collaborate across traditionally separated fields. For example, research to understand the successful implementation of post-exposure prophylaxis (PEP) would necessarily need a complementary component on acceptability and the impact of stigma and discrimination on care-seeking behaviours.

Research should be prioritized based upon its potential impact and likelihood of leading to transformative, effective, and efficient innovations. At the same time, operational research that leads to stronger programmatic capacity and informs integration with, and strengthening of, national public health and health systems is needed to ensure that these new technical innovations are accessible and scalable at the national and sub-national levels. The need for high-quality leprosy research studies meeting the standards required for inclusion in WHO Guidelines has been noted [12]. 
A major partner in developing the research agenda was LRI, which was launched in 2013. The LRI conducted a similar priority-setting process in 2018 to inform its investment priorities. LRI adopted an elegant mixedmethods approach to defining and evaluating research priorities [13]. A recent editorial [9] compared the outcomes of the GPZL and LRI approaches and showed that, while the outcomes were not identical they were well aligned, offering welcome validation of the findings and reassuring the GPZL that its process has produced a robust research agenda.

The eight finalized research areas, and the priorities identified for each research area, are summarised in the panel.

As with other NTDs, COVID-19 poses significant challenges to leprosy control. WHO has issued interim guidance for community-based programs in the context of the COVID-19 pandemic [14], and national programs are restarting program interventions while relevant research gradually resumes, as the situation allows. Of particular concern are delays in diagnosis and interruption of treatment that might translate into increased morbidity, incomplete cure and the spread of drug resistance.

\section{Panel: the research priorities to achieve zero leprosy \\ Diagnostics}

The development, standardization, and deployment of accurate diagnostic tests for the early detection of infection and disease is a top priority. This may include molecular-based [15, 16] and immunological tools [17] that require digital support. Because a diagnosis of leprosy is usually made on clinical signs and symptoms and there is no "gold standard" nor easy method to correlate infection to disease progression, patients are often diagnosed and treated late, increasing the likelihood of further transmission and disease-related disability. Contact screening may offer opportunities for early diagnosis $[18,19]$ and targeted interventions. Another priority is harmonization, i.e., validation and quality assurance programmes to ensure standard procedures, correct interpretation, and thus high confidence in test results [20].

\section{Digital technology and innovation}

Governments, policymakers, and other stakeholders are seeking scalable and sustainable digital health solutions that can be integrated into national health systems and, ideally, expanded to include other conditions [21]. Digital interventions such as eLearning, digital diagnostics, and geolocation of leprosy patients are priorities. A number of applications are under development, including digital registries; a leprosy referral and surveillance network among healthcare providers; tele-dermatology to support health workers with access to medical specialists [22]; and, smartphone apps to facilitate diagnosis and treatment for peripheral health workers [23]. Policy to support the practical implementation of these developments will also be needed.

\section{Disability}

The early detection and treatment of leprosy is critical to preventing disabilities [24]. Effective strategies for preventing and stopping disability exist and rehabilitation techniques are available [25], but more knowledge to inform the accessibility, effectiveness, and cost-effectiveness of services is needed, as are new tools to improve practice. Better understanding of the causes of disability and ways to optimize disease management, is required for marginalised and economically and socially poor communities. Evidence on the significance of early detection [24], including the impact of case-finding and contact-tracing strategies on the prevalence of leprosyrelated disabilities among new cases, will support morbidity prevention, as will work to better understand the pathophysiology, detection, and management of reactions. Minimizing the impact of living with impairments due to leprosy is another priority and requires studies on the prevention and treatment of disability and on the efficacy, accessibility, and effectiveness of rehabilitation services, assistive devices, and community-based rehabilitation programs [26]. Better estimates on the number of people disabled from leprosy (and their needs) and estimates of the burden of leprosy disability are necessary to understand and quantify the need and to allocate resources [27].

\section{Epidemiological modelling and investment case}

Decisions on the selection and implementation of leprosy interventions $[28,29]$ should be based on a robust analysis of the benefits, risks, and costs [30, 31]. These include a financial and cost analysis of leprosy and an estimate of its socioeconomic burden. Currently, such evidence is scarce. Transmission models should be improved, as epidemiologic modelling is a powerful tool to prioritize alternative tools and interventions and evaluate endgame strategies as donors commit to zero leprosy [32]. An Elimination Investment Case (EIC) provides a framework for a systematic assessment of what is needed to achieve zero leprosy and the challenges, risk, and sustainability of various initiatives [33, 34].

\section{Implementation research}

Implementation research is required to improve the functioning of national leprosy programs and to increase the effectiveness of collaborations with their long-term partners [35]. It is equally relevant to increasing the 
quality of leprosy data within countries and globally [36]. Priority operational issues include case mapping, data management, monitoring and surveillance, health systems strengthening, genetic and clinical drug resistance surveillance, and active case finding. Advances in mapping technologies such as global positioning systems and geographic information systems that combine discrete location data with mobile or static services [37, 38] have not yet been fully integrated by the leprosy community into routine operations to target interventions [39]. Better data are needed for decision-making [40]. The AIM Initiative (https://aiminitiative.org/) promotes integrated mapping of routine NTD data for evidence-based intervention planning. These operational research priorities can be pursued as individual topics or integrated into program evaluation targets, larger proposals and global health systems strengthening initiatives.

\section{Stigma}

Among the targets in ILEP's Triple Zero CampaignZero Transmission, Zero Disability, and Zero Discrimination-the third (which includes stigma and mental well-being) has received the least attention. This is despite stigma and attitudinal barriers being cited as major challenges by persons affected by leprosy [41]. Stigma is a barrier to zero leprosy in terms of missed prevention opportunities and access to treatment and appropriate case management, and improved mental well-being is central to reducing the burden of leprosy [42]. Interventions to reduce stigma such as support groups offering peer counselling, peer-to-peer networks led by local experts, socioeconomic development, and the involvement of persons affected in leprosy services have been studied but little standardization has been achieved [43]. Such interventions need to be validated in different settings $[44,45]$ and scale up must be explored in order to define standardized approaches.

\section{Post exposure prophylaxis (PEP) and transmission}

Evidence for the efficacy of PEP with single dose rifampicin (SDR) has been established through multiple studies [46-49]. Among current research, the Leprosy Post-Exposure Prophylaxis (LPEP) program focuses on feasibility and impact [50-52]. Issues related to acceptability, perception [53], drug resistance [54] and impact of the treatment among those at highest risk of disease remain to be studied. The PEOPLE trial evaluates different PEP regimens and delivery modalities; the PEP4LEP trial assesses multiple contact tracing and screening platforms; the MALTALEP trial [55] examined the benefits of immunization with Bacille Calmette-Guerin (BCG) alone or in combination with SDR; and the PEP++ study [56] aims to establish an enhanced chemoprophylaxis regimen for close contacts of persons with leprosy. Another unmet research question pertains to the effect of chemoprophylaxis on transmission.

Priorities for understanding $M$. leprae transmission are related to understanding human-to-human transmission [57]. One of the main challenges to interrupting transmission is the long incubation period, during which transmission to contacts is assumed to occur. Other transmission-related research priorities are transmission networks, the extent and epidemiological significance of non-human reservoirs, and host-pathogen interactions. A better understanding of these might facilitate the development of diagnostic tests for both infection as well as pre-clinical and clinical disease [58].

\section{Vaccines}

Until recently, immunotherapy options for leprosy were limited to the live vaccine BCG [59-61]. Renewed efforts to develop partially effective vaccines, such as different BCG strains, into improved leprosy vaccines $[62,63]$ have resulted in Mycobacterium indicus pranii (MIP), a whole cell vaccine of heat-killed mycobacteria [64]. The ideal vaccine against leprosy would need to induce strong, long-lasting $\mathrm{T}$ cell responses directed against $M$. leprae antigens, thereby limiting infection, preventing disease, and reducing bacterial transmission to others $[65,66]$. Only recently has it been practical to contemplate the development and delivery of a new generation of leprosy vaccines. Of critical relevance for such vaccines is the recent availability of adjuvants that enable a new generation of $\mathrm{T}$ cell vaccines. LepVax is a multivalent recombinant protein formulated in a modern adjuvant that is used in more than a dozen vaccine candidates and is a safe and effective inducer of durable $\mathrm{T}$ cell responses [67]. It has been suggested that LepVax might first be used as a curative rather than a prophylactic vaccine [67]. For both MIP and LepVax, however, full clinical trials and registration in multiple countries have yet to be achieved and safety monitoring must be established. In the case of curative vaccines, sensitive diagnostic tests are critical.

\section{Conclusions}

Despite the impact of MDT on leprosy, particularly in the 1990s, the number of reported cases remained stagnant over the last decade and concerns are growing that a significant number of cases may go unreported and undiagnosed [2,68]. In addition to traditional public health approaches such as active case finding [69], new techniques and innovations are needed: these require innovative, high-quality research and an engaged scientific community that is aligned and committed to addressing key research priorities [70]. 
The recent WHO Leprosy Guidelines highlighted the insufficient quality of leprosy research in many areas [71]. The establishment of the GPZL, a coalition of all key actors, in 2018 has already revitalized thinking towards leprosy control through extensive engagement with leprosy stakeholders and the NTD community as a whole. Experience with elimination efforts for other NTDs has highlighted the importance of this type of commitment and alignment $[72,73]$. For example, a comprehensive research agenda for the elimination of lymphatic filariasis (LF), commissioned by the Bill \& Melinda Gates Foundation in 2004 under the auspices of the Global Alliance to Eliminate Lymphatic Filariasis (GAELF), catalysed key scientific research, resulted in the development of new tools and strategies, and focused funding for LF elimination around priority strategies [74].

For LF and a few other NTDs, including schistosomiasis, a research agenda development process and research priorities were commissioned and funded almost in their entirety by a single donor, namely the Bill \& Melinda Gates Foundation. This has not been the case for leprosy. Thus, the challenge now is to mobilise resources to implement this research agenda, which will require further priority-setting and coordination on protocol development, the cooperation of experts and institutions with a wide range of expertise, availability of field sites, and very considerable financial investment.

The individual components of the research agenda vary in resource needs, will require distinct expertise, and will operate over different timescales. The stigma, disability, and PEP research plans are well advanced, with many activities in progress or even near implementation and scaling up. Epidemiologic modelling is being funded by the GPZL as part of its advocacy and resource mobilisation strategy in 2020. The operational research and digital health plans can be tackled and progress made in the short term, while innovations in the fields of diagnostics and vaccines will require much longer timescales.

The research agenda needs to be imaginatively yet loosely managed as there are considerable synergies between the different elements, such as PEP, vaccines, and diagnostics, yet research is notoriously unpredictable and progress cannot be fully controlled. Of particular importance is early input from stigma and disability experts in the development of tools and approaches that might touch on socially sensitive areas including concerns over disclosure and surveillance.

Developing and achieving consensus on the research agenda for zero leprosy is an important step forward for the leprosy community. The next step-further prioritization, partner alignment, resource mobilisation, planning, and coordination of the realisation of that research agenda-is equally critical. Moving towards zero leprosy requires investments from existing and new partners at all stages of the process, from discovery to implementation. Technical innovation is required to create the necessary tools for intervention and diagnosis. High-quality implementation research is needed to standardize those tools and bring them into national programs, supported by a strong evidence base. The G-FINDER report on research and development funding for NTDs including leprosy presents the scale of the current investment and the sources of funding [75]. However coordination is needed to ensure that resources are directed, in an impactful and measurable way, to the sustained, effective programs required to achieve zero leprosy. Ideally, coordination and control will increasingly be by the countries and communities most in need of innovations.

\section{Abbreviations}

BCG: Bacille Calmette-Guerin; GPZL: Global partnership for zero leprosy; LRI: Leprosy research initiative; MDT: Multi-drug therapy; MIP: Mycobacterium indicus pranii; NTDs: Neglected tropical diseases; PEP: Post-exposure prophylaxis; WHO: World Health Organization.

\section{Acknowledgements}

We thank all members and contributors to the working group. Robin Moseley provided editorial assistance.

\section{Authors' contributions}

All co-authors contributed to study design, data analysis, and manuscript writing including revision. All authors read and approved the final manuscript.

\section{Funding}

The authors received no specific funding for this work.

Availability of data and materials

From the GPZL.

Ethics approval and consent to participate

Not applicable.

\section{Consent for publication}

All participants are aware that the results will be made publicly available. All authors have seen and approved the final version of the manuscript.

\section{Competing interests}

CD is the secretariat director of the GPZL. FM was a staff of the Novartis Foundation at the time of the data collection. The authors declare that they have no competing interests.

\section{Author details}

1 Swiss Tropical and Public Health Institute, Socinstrasse 57, 4051 Basel, Switzerland. ${ }^{2}$ University of Basel, Basel, Switzerland. ${ }^{3}$ Global Partnership for Zero Leprosy, Task Force for Global Health, Decatur, GA, USA. ${ }^{4}$ Focus Area for Compassion and Ethics, Task Force for Global Health, Decatur, GA, USA. ${ }^{5}$ Novartis Foundation, Basel, Switzerland. ${ }^{6}$ University of Aberdeen, Aberdeen, UK.

Received: 12 August 2020 Accepted: 2 November 2020

Published online: 12 November 2020

References

1. Smith CS, Aerts A, Kita E, Virmond M. Time to define leprosy elimination as zero leprosy transmission? Lancet Infect Dis. 2016;16:398-9. 
2. WHO. Global leprosy update, 2018: moving towards a leprosy-free world. Wkly Epidem Rec. 2019a;2019(94):389-412.

3. WHO. Global leprosy (Hansen Disease) update, 2019: time to step-up prevention initiatives. Wkly Epidem Rec. 2019b;2020(95):417-40.

4. Smith CS, Aerts A, Saunderson P, Kawuma J, Kita E, Virmond M. Multidrug therapy for leprosy: a game changer on the path to elimination. Lancet Infect Dis. 2017;17:e293-7.

5. Britton WJ, Lockwood DN. Leprosy. Lancet. 2004;363:1209-19.

6. WHO. Global leprosy strategy 2016-2020. Accelerating towards a leprosyfree world. Geneva: World Health Organization; 2016a.

7. Tong A, Sainsbury P, Craig J. Consolidated criteria for reporting qualitative research (COREQ): a 32-item checklist for interviews and focus groups. Int J Qual Health Care. 2007;19:349-57.

8. Global Partnership for Zero Leprosy. GPZL reports on research priorities. Lepr Rev. 2019;90:237-89.

9. Scollard D. Leprosy research is a necessity. Lepr Rev. 2019;90:232-6.

10. Smith WC, Saunderson P. Leprosy. BMJ Clin Evid. 2010;2010:0915.

11. Scollard D, Gillis T. International Textbook of Leprosy. 2020. Available from https://internationaltextbookofleprosy.org/. Accessed 22 Oct 2020.

12. Schunemann HJ, Oxman AD, Brozek J, Glasziou P, Jaeschke R, Vist GE, et al. Grading quality of evidence and strength of recommendations for diagnostic tests and strategies. BMJ. 2008;336:1106-10.

13. Khazai Z, Van Brakel W, Essink D, Gillis T, Kasang C, Kuipers P, et al. Reviewing research priorities of the leprosy research initiative (LRI): a stakeholder's consultation. Lepr Rev. 2019;90:3-30.

14. WHO and UNICEF. Community-based health care, including outreach and campaigns, in the context of the COVID-19 pandemic. Geneva: World Health Organization and United Nations Children's Fund; 2020.

15. Barbieri RR, Manta FSN, Moreira SJM, Sales AM, Nery JAC, Nascimento LPR, et al. Quantitative polymerase chain reaction in paucibacillary leprosy diagnosis: a follow-up study. PLoS Negl Trop Dis. 2019;13:e0007147.

16. Martinez AN, Talhari C, Moraes MO, Talhari S. PCR-based techniques for leprosy diagnosis: from the laboratory to the clinic. PLoS NegI Trop Dis. 2014;8:e2655

17. van Hooij A, Fat EMTK, Richardus R, van den Eeden SJF, Wilson L, de Dood $\mathrm{CJ}$, et al. Quantitative lateral flow strip assays as user-friendly tools to detect biomarker profiles for leprosy. Sci Rep. 2016;6:34260.

18. Corstjens P, van Hooij A, Tjon Kon Fat EM, Alam K, Vrolijk LB, Dlamini S, et al. Fingerstick test quantifying humoral and cellular biomarkers indicative for M. leprae infection. Clin Biochem. 2019;66:76-82.

19. van Hooij A, Tjon Kon Fat EM, van den Eeden SJF, Wilson L, Batista da Silva $M$, Salgado CG, et al. Field-friendly serological tests for determination of M. leprae-specific antibodies. Sci Rep. 2017;7:8868.

20. van Hooij A, Tjon Kon Fat EM, Batista da Silva M, Carvalho Bouth R, Cunha Messias AC, Gobbo AR, et al. Evaluation of immunodiagnostic tests for leprosy in Brazil, China and Ethiopia. Sci Rep. 2018;8:17920.

21. Alami H, Gagnon MP, Fortin JP. Digital health and the challenge of health systems transformation. Mhealth. 2017:3:31.

22. Kanthraj GR. Patient-assisted teledermatology practice: what is it? When, where, and how it is applied? Indian J Dermatol Venereol Leprol. 2015:81:136-43.

23. Mieras LF, Taal AT, Post EB, Ndeve AGZ, van Hees CLM. The development of a mobile application to support peripheral health workers to diagnose and treat people with skin diseases in resource-poor settings. Trop Med Infect Dis. 2018:3:102.

24. van Brakel WH, Nicholls PG, Wilder-Smith EP, Das L, Barkataki P, Lockwood $\mathrm{DN}$, et al. Early diagnosis of neuropathy in leprosy-comparing diagnostic tests in a large prospective study (the INFIR cohort study). PLoS Negl Trop Dis. 2008;2:e212.

25. Ebenso J, Muyiwa LT, Ebenso BE. Self care groups and ulcer prevention in Okegbala. Nigeria Lepr Rev. 2009;80:187-96.

26. Li J, Mu H, Ke W, Bao X, Wang Y, Wang Z, et al. The sustainability of selfcare in two counties of Guizhou Province, Peoples' Republic of China. Lepr Rev. 2008;79:110-7.

27. Chandler DJ, Hansen KS, Mahato B, Darlong J, John A, Lockwood DN. Household costs of leprosy reactions (ENL) in rural India. PLoS Negl Trop Dis. 2015;9:e0003431.

28. Blok DJ, de Vlas SJ, Geluk A, Richardus JH. Minimum requirements and optimal testing strategies of a diagnostic test for leprosy as a tool towards zero transmission: a modeling study. PLoS Negl Trop Dis. 2018;12:e0006529.
29. Fischer EA, de Vlas SJ, Habbema JD, Richardus JH. The long-term effect of current and new interventions on the new case detection of leprosy: a modeling study. PLoS Negl Trop Dis. 2011;5:e1330.

30. Cochi SL, Dowdle WL. The eradication of infectious diseases. Understanding the lessons and advancing experience. In: Cochi S, Dowdle WR, editors. Disease eradication in the 21 st century: implications for global health. Cambridge, MA: MIT Press; 2011.

31. Medley GF, Blok DJ, Crump RE, Hollingsworth TD, Galvani AP, NdeffoMbah ML, et al. Policy lessons from quantitative modeling of leprosy. Clin Infect Dis. 2018;66:S281-5.

32. Blok DJ, de Vlas SJ, Fischer EA, Richardus JH. Mathematical modelling of leprosy and its control. Adv Parasitol. 2015;87:33-51.

33. Tiwari A, Richardus JH. Investment case concepts in leprosy elimination: a systematic review. Lepr Rev. 2016;87:2-22.

34. Thompson K, Rabinovich R, Conteh L, Emerson C, Hall B. Group report: developing an eradication investment case. In: Cochi S, Dowdle WR, editors. Disease eradication in the 21 st century: implications for global health. Cambridge, MA: MIT Press; 2011. p. 133-48.

35. Kiefer S, Knoblauch AM, Steinmann P, Barth-Jaeggi T, Vahedi M, Maher $\mathrm{D}$, et al. Operational and implementation research within Global Fund to Fight AIDS, Tuberculosis and Malaria grants: a situation analysis in six countries. Glob Health. 2017;13:22.

36. Simpson H, Quao B, van der Grinten E, Saunderson P, Ampadu E, KwakyeMaclean C, et al. Routine surveillance data as a resource for planning integration of NTD case management. Lepr Rev. 2018;89:178-96.

37. Bakker MI, Scheelbeek PFD, van Beers S. The use of GIS in leprosy control. Lepr Rev. 2009;80:327-31.

38. Penna ML, Wand-Del-Rey-de-Oliveira ML, Penna G. Spatial distribution of leprosy in the Amazon region of Brazil. Emerg Infect Dis. 2009;15:650-2.

39. Alencar CH, Ramos AN Jr, dos Santos ES, Richter J, Heukelbach J. Clusters of leprosy transmission and of late diagnosis in a highly endemic area in Brazil: focus on different spatial analysis approaches. Trop Med Int Health. 2012;17:518-25.

40. Raju MS, John AS, Kuipers P. What stops people completing multi-drug therapy? Ranked perspectives of people with leprosy, their head of family and neighbours-across four Indian states. Lepr Rev. 2015;86:6-20.

41. Yotsu RR. Integrated management of Skin NTDs—lessons learned from existing practice and field research. Trop Med Infect Dis. 2018;3:120.

42. Price VG. Factors preventing early case detection for women affected by leprosy: a review of the literature. Glob Health Action. 2017;10:1360550.

43. Heijnders M, Van Der Meij S. The fight against stigma: an overview of stigma-reduction strategies and interventions. Psychol Health Med. 2006;11:353-63.

44. Weiss MG, Doongaji DR, Siddhartha S, Wypij D, Pathare S, Bhatawdekar $\mathrm{M}$, et al. The Explanatory Model Interview Catalogue (EMIC). Contribution to cross-cultural research methods from a study of leprosy and mental health. Br J Psychiatry. 1992;160:819-30.

45. Stevelink SA, van Brakel WH. The cross-cultural equivalence of participation instruments: a systematic review. Disabil Rehabil. 2013;35:1256-68.

46. Reveiz L, Buendia JA, Tellez D. Chemoprophylaxis in contacts of patients with leprosy: systematic review and meta-analysis. Rev Panam Salud Publica. 2009;26:341-9.

47. Richardus JH. Chemoprophylaxis: sufficient evidence for starting implementation pilots. Lepr Rev. 2015;86:128-9.

48. Smith WC. Chemoprophylaxis in the prevention of leprosy. BMJ. 2008;336:730-1.

49. Moet FJ, Pahan D, Oskam L, Richardus JH, COLEP Study Group. Effectiveness of single dose rifampicin in preventing leprosy in close contacts of patients with newly diagnosed leprosy: cluster randomised controlled trial. BMJ. 2008:336:761-4.

50. Barth-Jaeggi T, Steinmann P, Mieras L, van Brakel W, Richardus JH, Tiwari A, et al. Leprosy Post-Exposure Prophylaxis (LPEP) programme: study protocol for evaluating the feasibility and impact on case detection rates of contact tracing and single dose rifampicin. BMJ Open. 2016;6:e013633.

51. Steinmann P, Cavaliero A, Aerts A, Anand S, Arif M, Ay SS, et al. The Leprosy Post-Exposure Prophylaxis (LPEP) programme: update and interim analysis. Lepr Rev. 2018;89:102-16.

52. Cavaliero A, Greter H, Fürst T, Lay S, Ay SS, Robijn J, et al. An innovative approach to screening and chemoprophylaxis among contacts of leprosy patients in low endemic settings: experiences from Cambodia. PLoS Negl Trop Dis. 2019;13:e0007039. 
53. Peters R, Mieras L, Subedi M, Apte H, Koesbardiati T, Banstola NL, et al. A single dose of rifampicin to prevent leprosy: qualitative analysis of perceptions of persons affected, contacts, community members and health professionals towards chemoprophylaxis and the impact on their attitudes in India, Nepal and Indonesia. Lepr Rev. 2018;89:335-52.

54. Mieras L, Anthony R, van Brakel W, Bratschi MW, van den Broek J, Cambau $E$, et al. Negligible risk of inducing resistance in Mycobacterium tuberculosis with single-dose rifampicin as post-exposure prophylaxis for leprosy. Infect Dis Poverty. 2016. https://doi.org/10.1186/s40249-016-0140-y.

55. Richardus RA, Alam K, Pahan D, Feenstra SG, Geluk A, Richardus JH. The combined effect of chemoprophylaxis with single dose rifampicin and immunoprophylaxis with BCG to prevent leprosy in contacts of newly diagnosed leprosy cases: a cluster randomized controlled trial (MALTALEP study). BMC Infect Dis. 2013;13:456.

56. Mieras LF, Taal AT, van Brakel WH, Cambau E, Saunderson PR, Smith WCS, et al. An enhanced regimen as post-exposure chemoprophylaxis for leprosy: PEP++. BMC Infect Dis. 2018;18:506.

57. Moet FJ, Pahan D, Schuring RP, Oskam L, Richardus JH. Physical distance, genetic relationship, age, and leprosy classification are independent risk factors for leprosy in contacts of patients with leprosy. J Infect Dis. 2006;193:346-53.

58. Mensah-Awere D, Bratschi MW, Steinmann P, Fairley JK, Gillis TP. Symposium report: developing strategies to block the transmission of leprosy. Lepr Rev. 2015;86:156-64.

59. Merle CS, Cunha SS, Rodrigues LC. BCG vaccination and leprosy protection: review of current evidence and status of BCG in leprosy control. Expert Rev Vaccines. 2010;9:209-22.

60. Cunha SS, Alexander N, Barreto ML, Pereira ES, Dourado I, Maroja Mde F, et al. BCG revaccination does not protect against leprosy in the Brazilian Amazon: a cluster randomised trial. PLoS Negl Trop Dis. 2008;2:e167.

61. Karonga Prevention Trial Group. Randomised controlled trial of single $B C G$, repeated BCG, or combined BCG and killed Mycobacterium leprae vaccine for prevention of leprosy and tuberculosis in Malawi. Lancet. 1996;348:17-24.

62. Sharma P, Mukherjee R, Talwar GP, Sarathchandra KG, Walia R, Parida SK, et al. Immunoprophylactic effects of the anti-leprosy Mw vaccine in household contacts of leprosy patients: clinical field trials with a follow up of 8-10 years. Lepr Rev. 2005;76:127-43.

63. Gupte MD, Vallishayee RS, Anantharaman DS, Nagaraju B, Sreevatsa, Balasubramanyam $\mathrm{S}$, et al. Comparative leprosy vaccine trial in south India. Indian J Lepr. 1998;70:369-88.
64. Talwar GP, Gupta JC, Mustafa AS, Kar HK, Katoch K, Parida SK, et al. Development of a potent invigorator of immune responses endowed with both preventive and therapeutic properties. Biologics. 2017;11:55-63.

65. Duthie MS, Balagon MF. Combination chemoprophylaxis and immunoprophylaxis in reducing the incidence of leprosy. Risk Manag Healthc Policy. 2016;9:43-53.

66. Schuring RP, Richardus JH, Pahan D, Oskam L. Protective effect of the combination BCG vaccination and rifampicin prophylaxis in leprosy prevention. Vaccine. 2009;27:7125-8.

67. Duthie MS, Pena MT, Ebenezer GJ, Gillis TP, Sharma R, Cunningham K, et al. LepVax, a defined subunit vaccine that provides effective pre-exposure and post-exposure prophylaxis of M. leprae infection. NPJ Vaccines. 2018;3:12.

68. Smith WC, van Brakel W, Gillis T, Saunderson P, Richardus JH. The missing millions: a threat to the elimination of leprosy. PLoS Negl Trop Dis. 2015;9:e0003658.

69. WHO. Global leprosy strategy 2016-2020. Accelerating towards a leprosyfree world. Operational manual. Geneva: World Health Organization; 2016b.

70. Steinmann P, Reed SG, Mirza F, Hollingsworth TD, Richardus JH. Innovative tools and approaches to end the transmission of Mycobacterium leprae. Lancet Infect Dis. 2017;17:e298-305.

71. WHO. Guidelines for the diagnosis, treatment and prevention of leprosy. New Delhi: World Health Organization, Regional Office for South-East Asia; 2018.

72. Prichard RK, Basáñez MG, Boatin BA, McCarthy JS, Garcia HH, Yang GJ, et al. A research agenda for helminth diseases of humans: intervention for control and elimination. PLoS Negl Trop Dis. 2012;6:e1549.

73. Osei-Atweneboana MY, Lustigman S, Prichard RK, Boatin BA, Basáñez MG. A research agenda for helminth diseases of humans: health research and capacity building in disease-endemic countries for helminthiases control. PLoS Negl Trop Dis. 2012;6:e1602.

74. Boatin BA, Basáñez MG, Prichard RK, Awadzi K, Barakat RM, Garcia HH, et al. A research agenda for helminth diseases of humans: towards control and elimination. PLoS Negl Trop Dis. 2012;6:e1547.

75. G-Finder. Neglected diseases research and development: uneven progress. Policy Cures Research; 2019.
Ready to submit your research? Choose BMC and benefit from:

- fast, convenient online submission

- thorough peer review by experienced researchers in your field

- rapid publication on acceptance

- support for research data, including large and complex data types

- gold Open Access which fosters wider collaboration and increased citations

- maximum visibility for your research: over $100 \mathrm{M}$ website views per year

At $\mathrm{BMC}$, research is always in progress.

Learn more biomedcentral.com/submissions 